\title{
Impact of tailored water chemistry aqueous ions on foam stability enhancement
}

\author{
Zuhair AlYousef $^{1} \cdot$ Subhash Ayirala ${ }^{1} \cdot$ Majed Almubarak ${ }^{2} \cdot$ Dongkyu Cha $^{1}$
}

Received: 13 April 2021 / Accepted: 11 June 2021 / Published online: 19 July 2021

(c) The Author(s) 2021

\begin{abstract}
Generating strong and stable foam is necessary to achieve in-depth conformance control in the reservoir. Besides other parameters, the chemistry of injection water can significantly impact foam generation and stabilization. The tailored water chemistry was found to have good potential to improve foam stability. The objective of this study is to extensively evaluate the effect of different aqueous ions in the selected tailored water chemistry formulations on foam stabilization. Bulk and dynamic foam experiments were used to evaluate the impact of different tailored water chemistry aqueous ions on foam generation and stabilization. For bulk foam tests, the stability of foams generated using three surfactants and different aqueous ions was analyzed using bottle tests. For dynamic foam experiments, the tests were conducted using a microfluidic device. The results clearly demonstrated that the ionic content of aqueous solutions can significantly affect foam stabilization. The results revealed that the foam stabilization in bulk is different than that in porous media. Depending on the surfactant type, the divalent ions were found to have stronger influence on foam stabilization when compared to monovalent ions. The bulk foam results pointed out that the aqueous solutions containing calcium chloride salt $\left(\mathrm{CaCl}_{2}\right)$ showed longer foam life with the anionic surfactant and very weak foam with the nonionic surfactant. The solutions with magnesium chloride $\left(\mathrm{MgCl}_{2}\right)$ and $\mathrm{CaCl}_{2}$ salts displayed higher impact on foam stability in comparison with sodium chloride $(\mathrm{NaCl})$ with the amphoteric alkyl amine surfactant. Less stable foams were generated with aqueous solutions comprising of both magnesium and calcium ions. In the microfluidic model, the solutions containing $\mathrm{MgCl}_{2}$ showed higher resistance to gas flow and subsequently higher mobility reduction factor for the injection gas when compared to those produced using $\mathrm{NaCl}$ and $\mathrm{CaCl}_{2}$ salts. This experimental study focusing about the role of different aqueous ions in the injection water on foam could help in better understanding the foam stabilization process. The new knowledge gained can also enable the selection and optimization of the right injection water chemistry and suitable chemicals for foam field applications.
\end{abstract}

Keywords Foam stability $\cdot$ Tailored water chemistry $\cdot$ Aqueous ions

\section{Introduction}

The number of new field discoveries has been declining in recent years, and the remaining oil after the application of common recovery methods is also significant in existing fields (Manrique et al. 2010). To keep up with the rising demand for energy, various technologies that can improve oil recovery need to be investigated.

Zuhair AlYousef

zuhair.alyousef@gmail.com

Saudi Aramco, Dhahran, Saudi Arabia

2 Massachusetts Institute of Technology, Cambridge, MA, USA
Enhanced oil recovery (EOR) refers to the augmentation of natural energy through the injection of fluids to displace oil toward producing wells (Babadagli 2020). The injected fluids create favorable conditions for oil recovery such as oil swelling, oil viscosity reduction, and wettability alteration (Manrique et al. 2010). EOR methods include gas flooding, chemical flooding, steam flooding, and low salinity water (LSW) flooding (Bera and Belhaj 2016). Moreover, the ultimate goal of any EOR method is to reduce the residual oil saturation which is controlled by the interactions at the pore scale.

Gas flooding involves injecting gasses such as hydrocarbon gas, nitrogen, carbon dioxide, or flue gas into oil reservoirs that have been waterflooded (Whorton and Kieschnick 1950; Liu et al. 2011). Whorton et al. (1952) were granted 
the first patent introducing the concept of $\mathrm{CO}_{2}$ as a means for producing oil. While gas injection in theory can displace virtually all the oil in the volume swept by the gas, this technique suffers from some major drawbacks such as inadequate mobility control and poor reservoir conformance. The high mobility and low density of gas compared to reservoir fluids can potentially lead to gravity override, viscous fingering, and channeling through high permeability streaks or fractures (Campbell and Orr 1985; Masalmeh et al. 2010).

Foam is defined as dispersion of gas in continuous liquid phase (Falls et al. 1988; AlYousef and Schechter 2019). Because foams are thermodynamically unstable, surfactants are usually used to make them stable. Surfactants can adsorb at the gas-liquid interface, reducing the interfacial tension and generating the foam. Foam generation generally increases with surfactant concentration up to the critical micelle concentration (CMC) above which surfactant concentration has little impact (Chiang et al. 1980). Several parameters could impact foam generation and stabilization including: surfactant type and concentration, temperature, pressure, gas saturation, water salinity and chemistry, presence of crude oil, rock-fluid interactions, and capillary forces (Figdore 1982; Al-Hashim et al. 1988; Mannhardt et al. 1993; AlYousef et al. 2020a, b; Almobarky et al. 2020; Wang et al. 2018, Ranjan et al. 2020). Foams are typically described in terms of their foamability and stability. Foamability is the ability of the gas-liquid system to generate the foam, whereas the stability describes the variation of foam height or volume with time, immediately after foam generation. Foam stability is dependent on electric double-layer repulsion, gravity drainage, capillary suction, surface elasticity, dispersion force, steric repulsion, and surface and bulk viscosity (Malysa and Lunkenheimer 2008, Schramm and Wassmuth 1994).

The in-situ generation of foam offers a potential solution to the shortcomings of gas injection (Holbrook 1958; Kovscek and Radke 1994; Enick et al. 2012). Foam can deliver a more favorable mobility ratio by increasing the gas apparent viscosity and reducing its relative permeability (Almajid and Kovscek 2020; AlYousef et al. 2020a, b). However, the mobility of foam is highly vulnerable at harsh temperature, pressure, and salinity conditions (Grigg et al. 2004; Almajid and Kovscek 2016; Almobarky et al. 2020; Fuseni et al. 2018).

Waterflooding has been extensively practiced worldwide for oil recovery (Nasralla et al. 2011). It consists of injecting water to pressurize the reservoir and sweep oil via pistonlike displacement. Waterflooding uses large quantities of water and researchers have studied the applicability of seawater as a source of injection water in this method (Osode et al. 2015). Injecting seawater can cause inorganic scale precipitation, thereby necessitating the treatment of seawater to remove harmful ions and prevent them from precipitating and causing reservoir damage (Almubarak et al. 2019).

Tailoring injection water salinity and ionic composition have shown significant potential in both sandstone and carbonate reservoirs to improve recovery (Yousef et al. 2012; Yousef and Ayirala 2014; Teklu et al. 2016). Webb et al. (2004) reported a $25-50 \%$ reduction in residual oil saturation after injecting LSW. Even though the main recovery mechanisms of LSW injection are still debated, the general consensus among researchers is that modifying the ionic composition of the injected water can create a wetting state more favorable for oil recovery (Alotaibi et al. 2011; Nasralla et al. 2011; Lee et al. 2010).

The "hybrid approach" of combining EOR processes has been gaining a lot of interest lately (Manrique et al. 2010; Ayirala and Yousef 2015; Singh and Mohanty 2016; AlSofi et al. 2018; Shabib-AsL et al. 2019; AlYousef et al. 2020a, b). The chemical structure of foaming agent, rock minerals and composition, type of gas, reservoir fluids and conditions as well as water chemistry are the critical parameters that can determine the stability and mobility control of foam floods (Farajzadeh et al. 2010; Farajzadeh et al. 2012; Kapetas et al. 2015; Eide et al. 2018; AlMatouq et al. 2020). The synergy of LSW and foaming agents may offer a novel technique of altering the rock wettability for EOR in addition to generating stronger and stable foams for gas mobility applications. A recent study by AlYousef et al. (2020a, b) suggested that depending on the surfactant type, ten times dilution of the high salinity water (HSW) can produce foam with the highest stability and strength. Furthermore, the synergistic effect of LSW and foaming agents can be used to enhance foam stability, and consequently improve oil recovery.

The objective of this study is to extensively evaluate the effect of different aqueous ions in the selected tailored water chemistry formulations that were previously described and used by AlYousef et al. (2020a, b) on foam stabilization and mobility control. Both static bulk tests and dynamic foam tests in porous media were conducted at ambient conditions using several tailored brine recipes comprising of different aqueous ions to achieve this objective. The temperature and pressure have significant impact on foam stability wherein both can influence the phase behavior of fluids, and the temperature can significantly impact the thermal stability of solutions. As a result, similar tests will be conducted for the next phase of this study at elevated temperature and pressure conditions.

\section{Materials}

Three different surfactants were used in this study. One of the surfactants used is an anionic surfactant, which contains alpha olefin sulfonate, isopropyl alcohol, and citrus 
Table 1 List of foaming agents (surfactants)

\begin{tabular}{ll}
\hline Surfactant & Name \\
\hline Surfactant 1 & Alpha olefin sulfonate \\
Surfactant 2 & Amphoteric alkyl amine \\
Surfactant 3 & NEODOL 25-12 \\
\hline
\end{tabular}

terpenes. Also, amphoteric alkyl amine and commercially available $100 \mathrm{wt} \%$ active nonionic surfactant (NEODOL 25-12) are used for comparative evaluation. Table 1 reports these surfactants and their naming conventions used in this study. Three different brine recipes of different individual ions (W1, W2, and W3) are used to investigate the effect of individual aqueous ions in the selected tailored water chemistry formulations on foam stabilization and mobility control. More details on the brine compositions can be found in Table 2. As stated earlier, a previous study (AlYousef et al. 2020a, b) suggested that ten times dilution of the HSW (LSW3) can produce the most stable and viscous foams when compared to the other low salinity brine formulations (LSW1 and LSW2). The compositions of the HSW and tailored water chemistry formulations (LSW1, LSW2, and LSW3) used in that study are also listed in Table 2. The gas used for foam generation is carbon dioxide gas $\left(\mathrm{CO}_{2}\right)$, industrial grade.

\section{Methodology}

The effect of different aqueous ions: sodium ions $\left(\mathrm{Na}^{+}\right)$, chloride ions $\left(\mathrm{Cl}^{-}\right)$, magnesium ions $\left(\mathrm{Mg}^{2+}\right)$, and calcium ions $\left(\mathrm{Ca}^{2+}\right)$ in the selected tailored water chemistry formulations on foam stabilization and strength was studied using both static and dynamic foam tests. Sodium chloride $(\mathrm{NaCl})$, calcium chloride $\left(\mathrm{CaCl}_{2}\right)$, and magnesium chloride $\left(\mathrm{MgCl}_{2}\right)$ salts were used to prepare the water formulations. The static test includes foam bulk test, while foam dynamic tests include foam apparent viscosity in porous media (microfluidic chip). The objectives and detailed descriptions for each of these tests are stated below.

\section{Static tests}

Static foam tests are generally used to conduct fast screening on foam stability, especially when new chemicals or solutions are being evaluated for the first time. The objectives of this test here are to assess surfactant solutions stability and evaluate foam stability and strength by quantifying the foam life over time. To prepare the solutions, a total of 12 samples of $15 \mathrm{ml}$ solutions were first prepared by mixing the foaming agent (surfactant) with water 1 (W1), water 2 (W2), water 3 (W3), and HSW at 300 RPM for few hours using a magnetic stirrer. The surfactant solutions were prepared using 5 gallons per thousand gallons (gpt) of surfactant 1 and surfactant 2 , while $0.20 \mathrm{wt} . \%$ was used to prepare the solutions of surfactant 3 . Then, $5 \mathrm{ml}$ of each solution was poured into a $13 \mathrm{ml}$ vial. This results in a foam quality (ratio of gas to fluids) of around $62 \%$. The foam was generated by shaking each test tube for $2 \mathrm{~min}$, and then the foam images over time were captured. Foam images were uploaded to Image-J software to measure the foam height over time and determine the foam half-life. These tests were conducted at $25{ }^{\circ} \mathrm{C}$.

\section{Foam in porous media}

Foam generation and stabilization in porous media are different than that generated in bulk (static foam). Consequently, it is very important to evaluate the dynamic foam properties in porous media and compare it to that generated in bulk foam. The major objectives of dynamic foam tests were to ensure the foam generation and also evaluate the effect of different aqueous ions on foam stability and apparent viscosity in porous media. The effectiveness of foam to reduce gas mobility in porous media is mostly evaluated using the dynamic foam tests. The evaluation of the impact of different individual aqueous ions on foam stability and strength in porous media was conducted using $\mathrm{CO}_{2}$ gas.

The strength and stability of $\mathrm{CO}_{2}$ foams generated using surfactant 1 , surfactant 2 , and surfactant 3 in various water formulations: W1, W2, and W3 (listed in Table 2) were measured using microfluidics device as shown in Fig. 1.

Table 2 Brine compositions

\begin{tabular}{lllllllll}
\hline Ions & Symbol & $\begin{array}{l}\text { HSW } \\
(\mathrm{ppm})\end{array}$ & $\begin{array}{l}\text { LSW1 } \\
(\mathrm{ppm})\end{array}$ & $\begin{array}{l}\text { LSW2 } \\
(\mathrm{ppm})\end{array}$ & $\begin{array}{l}\text { LSW3 } \\
(\mathrm{ppm})\end{array}$ & $\begin{array}{l}\text { W1 } \\
(\mathrm{ppm})\end{array}$ & $\begin{array}{l}\text { W2 } \\
(\mathrm{ppm})\end{array}$ & $\begin{array}{l}\text { W3 } \\
(\mathrm{ppm})\end{array}$ \\
\hline Sodium & $\mathrm{Na}^{+}$ & 18,300 & 1865 & 721 & 1824 & 2266 & - & - \\
Calcium & $\mathrm{Ca}^{2+}$ & 650 & - & 228 & 65 & - & 2081 & - \\
Magnesium & $\mathrm{Mg}^{2+}$ & 2110 & - & 741 & 211 & - & - & 1471 \\
Sulfate & $\mathrm{SO}_{4}{ }^{2-}$ & 4290 & 3896 & 1506 & 429 & - & - & - \\
Chloride & $\mathrm{Cl}^{-}$ & 32,200 & - & 2562 & 3220 & 3494 & 3681 & 4290 \\
Bicarbonate & $\mathrm{HCO}_{3}^{-}$ & 120 & - & - & 12 & & - & - \\
TDS & & 57,670 & 5761 & 5761 & 5761 & 5761 & 5761 & 5761 \\
\hline & & & & & & & & \\
\end{tabular}


Fig. 1 Microfluidic apparatus

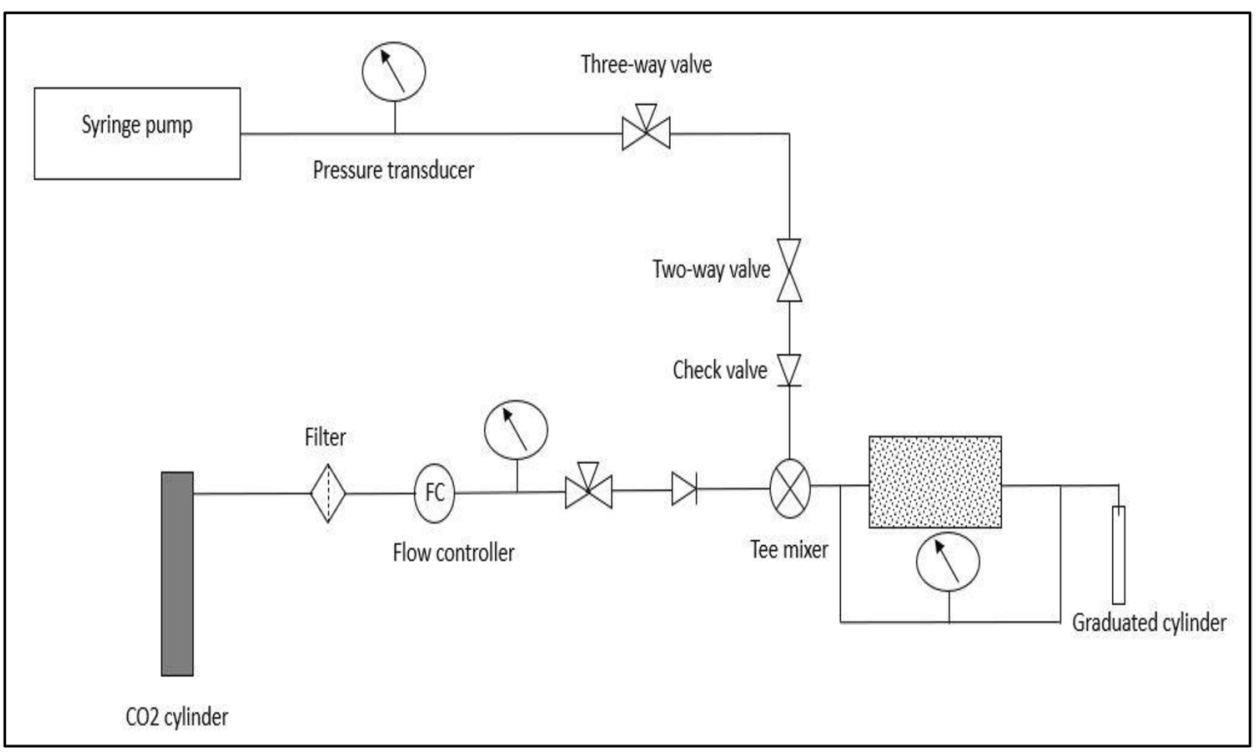

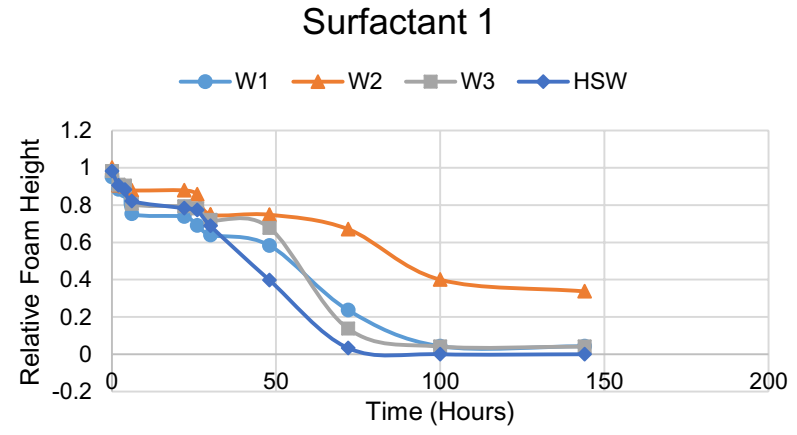

Fig. 2 Relative foam height for surfactant 1 with W1, W2, W3, and HSW formulations

The microfluidic chip used in this study has a uniform network, porosity of $57 \%$, and permeability of 2.50 Darcy. The dimensions of chip used are $20 \times 10 \times 0.02 \mathrm{~mm}$. The experiments were conducted at atmospheric pressure and room temperature $\left(25^{\circ} \mathrm{C}\right)$. To evaluate the impact of different ions on foam strength, pressure drop across the microfluidic chip was measured for $70 \%$ and $90 \%$ foam quality, and the total injection rate was set to $50 \mu \mathrm{L} / \mathrm{min}$.

\section{Results and discussion}

\section{Static tests}

In this study, the static foam tests were conducted for three surfactants to investigate the effect of different aqueous ions: $\mathrm{Na}^{+}, \mathrm{Cl}^{-}, \mathrm{Mg}^{2+}$, and $\mathrm{Ca}^{2+}$ on foam stability and strength. The surfactant solution prepared using HSW

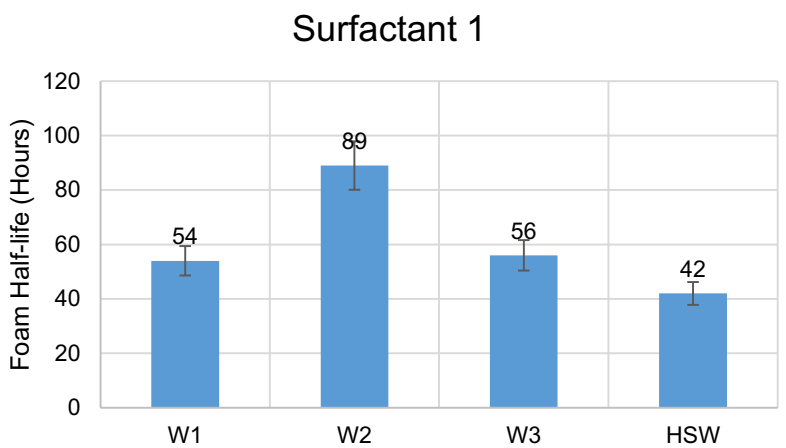

Fig. 3 Foam half-life for surfactant 1 with W1, W2, W3, and HSW formulations

was used for comparison purpose. For surfactant 1 , the results demonstrated that different ions can strongly affect the foam stability and thus the foam life. As shown in Fig. 2, all surfactant solutions were able to produce full columns of foam as the relative foam height (foam height/ maximum foam height) is equal to one for studied cases. The results also demonstrated that the surfactant solution prepared using W2 produced foam with the highest stability followed by W1 and W3 solutions. Surfactant solution prepared using HSW produced the foam with the least stability and strength when compared to the three water solutions. The foam half-life for each solution was estimated from the data plotted in Fig. 2. As depicted in Fig. 3, the foam half-life for W1, W2, W3, and HSW were 54, 89, 56 , and $42 \mathrm{~h}$, respectively. As reported earlier, surfactant 1 is an anionic surfactant. W2 solution contains $\mathrm{Ca}^{2+}$ and $\mathrm{Cl}^{-}$, and the results showed that $\mathrm{CaCl}_{2}$ produced the foam with the highest stability, almost $60-65 \%$ higher than the 


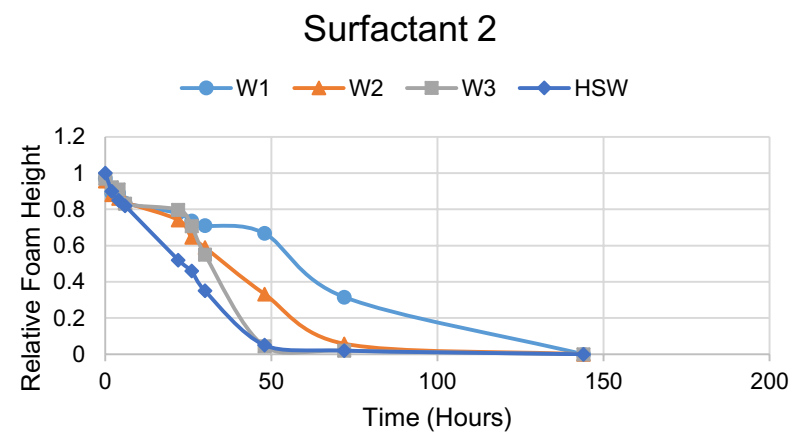

Fig. 4 Relative foam height for surfactant 2 with W1, W2, W3, and HSW formulations

other solutions comprising of $\mathrm{MgCl}_{2}$ and $\mathrm{NaCl}$ salts. Also, the solutions containing $\mathrm{NaCl}$ and $\mathrm{MgCl}_{2}$ had almost the same impact on foam stability. The presence of different multi-ions, as those in HSW, had negative impact on foam stability and seems to destabilize the foam faster when compared to the other water solutions. The bulk foam results presented here clearly reflect the role of different ions on foam stability.

The results obtained with surfactant 2 , an amphoteric surfactant, also demonstrated the influence of different individual aqueous ions on foam stability. As shown in Fig. 4 and similar to what have been reported for surfactant 1 solutions, all surfactant solutions were able to produce full columns of foam. The results showed that $\mathrm{W} 1$ had the highest foam stability when compared to the other water solutions. It has also been demonstrated that W2 and W3 solutions had better stability than HSW solution. Both W2 and W3 solutions produced almost the similar foam with same stability. According to these results, the solutions containing $\mathrm{MgCl}_{2}$ and $\mathrm{CaCl}_{2}$ tend to destabilize the foam faster when compared to the solution prepared using $\mathrm{NaCl}$ salt. This means that the divalent cations will have significant impact on foam stability when compared to the monovalent cations for this type of surfactant. Even though the three formulations (W1, W2, and W3) comprised the same total dissolved salts (TDS), each formulation showed different foam stability behavior. Such difference is mainly due to the variations in ionic content and ionic strength for each water formulation. Figure 5 presents the summary of foam half-life results obtained for different surfactant 2 cases. The foam half-life for W1, W2, W3, and HSW were 60, 36, 32, and 23 h, respectively. For HSW solution, the presence of different multi-ions tends to destabilize the foam faster when compared to the other water solutions. The foam half-life of HSW solution is about onethird that of W1 solution.

Surfactant 3 is a non-ionic surfactant. The results on generated foam with this type of surfactant using four different

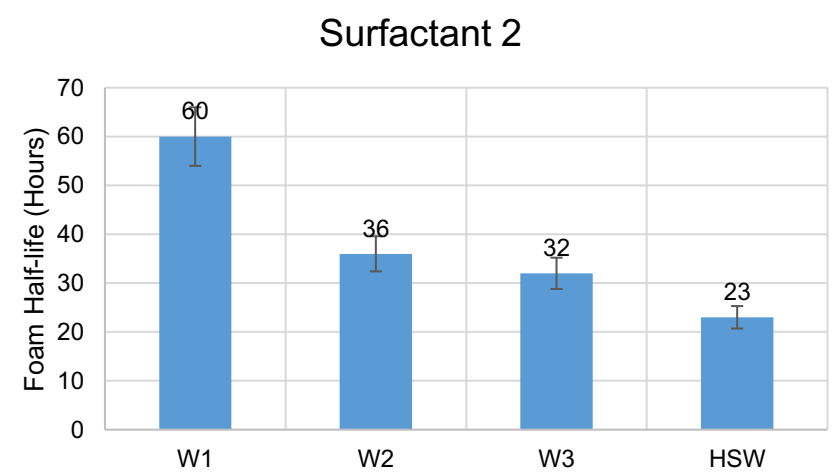

Fig. 5 Foam half-life data for surfactant 2 with W1, W2, W3, and HSW formulations

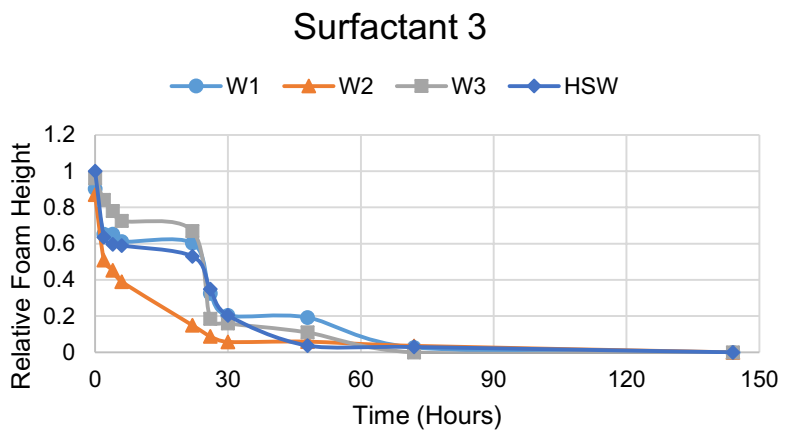

Fig. 6 Relative foam height for surfactant 3 with W1, W2, W3, and HSW formulations

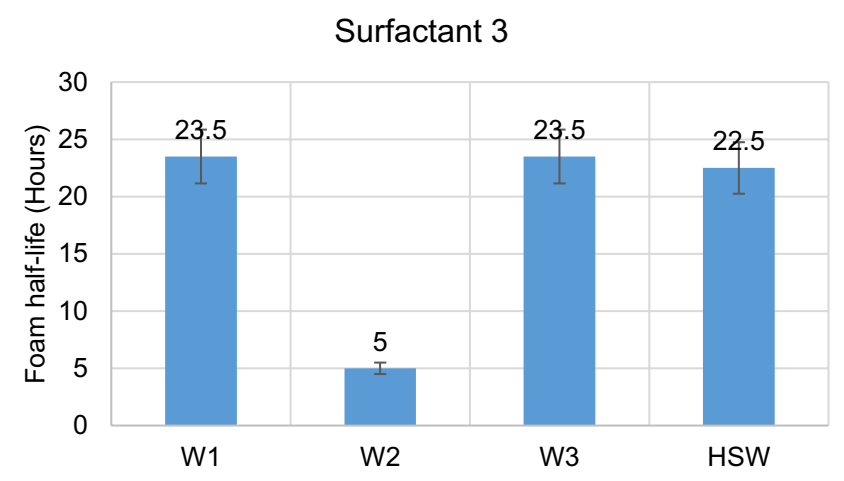

Fig. 7 Foam half-life data for surfactant 3 with W1, W2, W3, and HSW formulations

water formulations showed that the different ions used in this study had an impact on foam stability, especially when $\mathrm{CaCl}_{2}$ salt was used. Compared to surfactant 1 and surfactant 2 , surfactant 3 influenced significantly by all tested ions. As shown in Fig. 6, the foam height dropped significantly within the first $30 \mathrm{~h}$. Also, the results revealed that $\mathrm{W} 1, \mathrm{~W} 3$, and HSW solutions had almost the same response, while W2 
formulation showed the lowest foam stability. In addition to the weak foam stability behavior reported for $\mathrm{W} 2$ formulation, its foamability (ability to generate foams) was also poor since its initial relative foam height was relatively low when compared to the other water solutions. Figure 7 shows the summary of foam half-life results obtained for different surfactant 3 cases. The foam half-life for W1, W2, W3, and HSW were $23.5,5,23.5$, and $22.5 \mathrm{~h}$, respectively.

\section{Foams in porous media}

As mentioned previously, foam generation and stabilization in porous media are different than that generated in bulk. In addition to the solution's properties and experimental conditions, the porous media features considerably impact the foam characteristics (generation and stabilization). $\mathrm{CO}_{2}$ foam strength produced using surfactant 1 , surfactant 2 , and surfactant 3 formulations in various brines (W1, W2, and W3) was measured using microfluidic device. Pressure drop values across the microfluidics chip as a result of the generated foam within the porous structure of microfluidic chip are measured for each surfactant using the three water formulations. Higher pressure drops correspond to higher resistance to gas flow and, hence, foams with higher apparent viscosity. The baseline experiment was conducted by injecting only water into the microfluidic chip. The measured pressure drop across the microfluidic chip was around 5 psi. For surfactant 1 solutions and as presented in Fig. 8, it can be seen that almost all water formulations produced the same pressure responses. The average pressure drops for foam generated at $70 \%$ foam quality using W1, W2, and W3 water formulations were about 21.8, 22.6, and $20.6 \mathrm{psi}$, respectively. This means all tested ions in the three salts $\mathrm{NaCl}, \mathrm{CaCl}_{2}$, and $\mathrm{MgCl}_{2}$ had the same impact on foam stability in porous media. Similar results were obtained for foam generated using $90 \%$ foam quality. Figure 9 summarizes the average pressure drop for foam generated at $70 \%$ and $90 \%$ foam quality using the three water formulations.

\section{Surfactant 1}

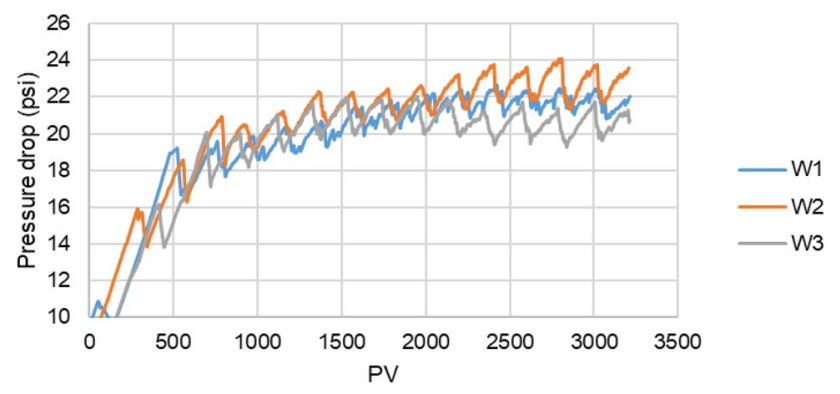

Fig. 8 Pressure drop values recorded across microfluidic chip during flow of $\mathrm{CO}_{2}$ foam produced using surfactant 1 solution at $70 \%$ foam quality in different aqueous solutions

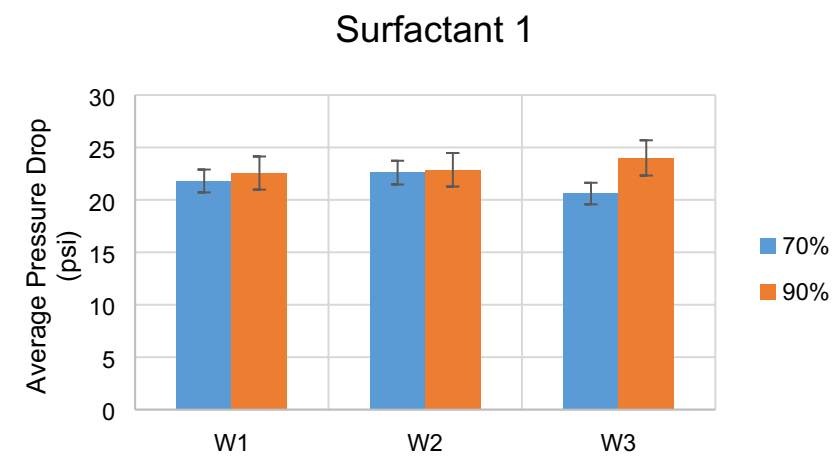

Fig. 9 Average pressure drop values recorded across microfluidic chip during flow of $\mathrm{CO}_{2}$ foam produced using surfactant 1 solution at $70 \%$ and $90 \%$ foam quality in different aqueous solutions

Even though the bulk foam results presented earlier showed that W2 solution produced the most stable foams with this type of surfactant, the results of foam in porous media suggest that all tested ions had the same impact on foam stability. These findings agree with the previously reported results of AlYousef et al. (2020a, b) by using LSW2 and LSW3 brines. It was also inferred from this previous study that foam generation and stability are influenced by the interactions of all ions present in the aqueous phase and that there is no specific ion which can significantly impact the foam behavior. All these observations intuitively suggest the balance among all aqueous ions existing in the brine solution is the key for foam stabilization.

The results for surfactant 2 solutions tested at $70 \%$ and $90 \%$ foam quality showed that each tested ion can fairly impact the foam stability. As plotted in Fig. 10 for the foam generated using $70 \%$ foam quality, the highest pressure drops were observed when the $\mathrm{CO}_{2}$ foam was produced using W3 formulation. The average pressure drop for this case was about 48.5 psi. The second highest was reported when the $\mathrm{CO}_{2}$ foam was produced using $\mathrm{W} 2$ formulation. The average

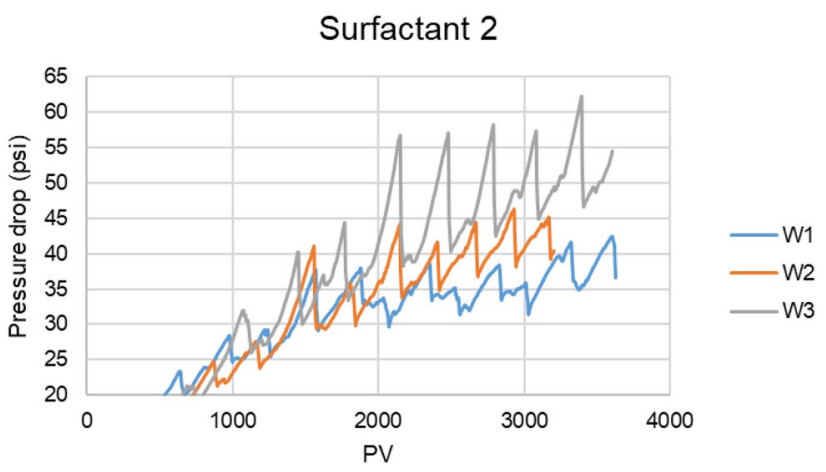

Fig. 10 Pressure drop values recorded across microfluidic chip during flow of $\mathrm{CO}_{2}$ foam produced using surfactant 2 solution in different aqueous solutions 
pressure drops for foam generated using W2 water formulations were about $40 \mathrm{psi}$. The least viscous foams were generated for $\mathrm{W} 1$ formulation with an average pressure drop of 36 psi. The calculated foam apparent viscosity for W1, $\mathrm{W} 2$, and $\mathrm{W} 3$ water formulations were $7.5 \mathrm{cP}, 8.5 \mathrm{cP}$, and 10 $\mathrm{cP}$, respectively. The average pressure drops for surfactant 2 solutions tested at $70 \%$ and $90 \%$ foam quality are summarized in Fig. 11. This surfactant is known to have good tolerance to salinity. As a result, it can be seen clearly that it produced more stable foams in porous media when divalent ions $\mathrm{Mg}^{2+}$ and $\mathrm{Ca}^{2+}$ were used. The results obtained with this type of surfactant provided an excellent example to clearly demonstrate the differences of foam behavior in bulk and porous media. The results for the bulk foam showed that W1 formulation produced the foam with the highest stability, whereas the results in porous media demonstrated that $\mathrm{W} 1$ formulation had the least stable and viscous foam.

$\mathrm{CO}_{2}$ foam strength produced using surfactant 3 solutions in various water formulations was also measured and foam apparent viscosities were also calculated. From the data presented in Fig. 12 for $70 \%$ foam quality, it can be seen that the highest steady state pressure drop was observed when the $\mathrm{CO}_{2}$ foam was produced using $\mathrm{W} 3$ formulation. This means the water containing magnesium ions $\left(\mathrm{Mg}^{2+}\right)$ and chloride ions $\left(\mathrm{Cl}^{-}\right)$produced the most stable foams among all the other tested water formulations. Interestingly, almost similar pressure difference data were obtained for foams generated using the solutions in W1 and W2 formulations. Such result indicates similar effects of these two water formulations on foam stability and eventually mobility in porous media. The average pressure drops for foam generated using W1 and W2 water formulations were about $17 \mathrm{psi}$, while the average pressure drop for W3 water formulation was about 28 psi. The calculated foam apparent viscosity for $\mathrm{W} 1, \mathrm{~W} 2$, and W3 water formulations were around $3.5 \mathrm{cP}, 3.5 \mathrm{cP}$, and 6 $\mathrm{cP}$, respectively. Figure 13 also presents the average pressure drop measured at $70 \%$ and $90 \%$ foam quality. There is

\section{Surfactant 2}

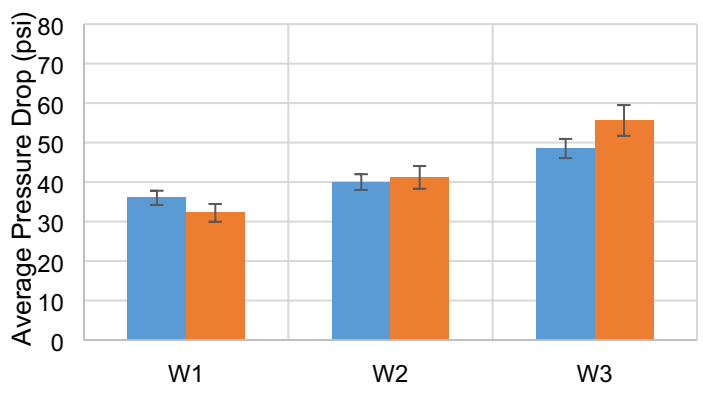

Fig. 11 Average pressure drop values recorded across microfluidic chip during flow of $\mathrm{CO}_{2}$ foam produced using surfactant 2 solution at $70 \%$ and $90 \%$ foam quality in different aqueous solutions

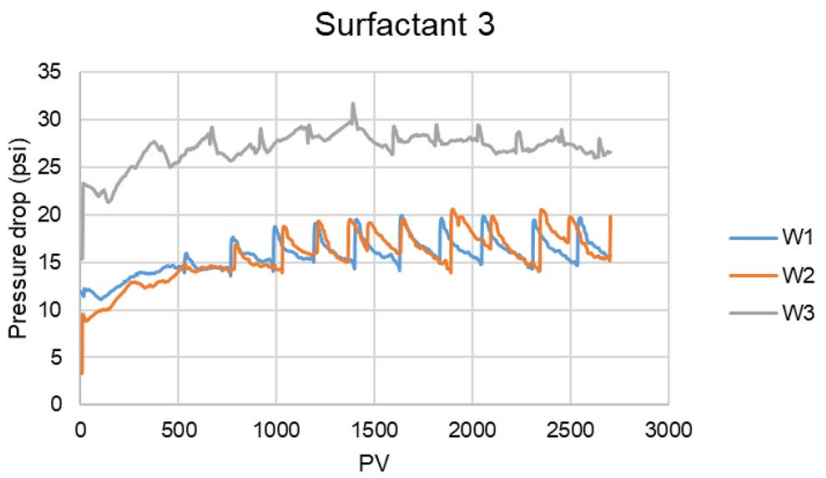

Fig. 12 Pressure drop values recorded across microfluidic chip during flow of $\mathrm{CO}_{2}$ foam produced using surfactant 3 solution in different aqueous solutions

good agreement between the two results obtained at $70 \%$ and $90 \%$ foam quality. Again, the foam behavior observed in porous media is different than that in bulk tests. In the static foam tests, W2 formulation produced very weak foams when compared to all other water formulations. However, the results of foam in porous media revealed that $\mathrm{W} 1$ and W2 formulations had almost same responses.

The results reported from this study suggested that the divalent ions have a stronger influence on foam stabilization when compared to monovalent ions. Also, it was found that the surfactant type can significantly influence the foam stability in the presence of different type of aqueous ions. Moreover, the results obtained from the bulk foam test are different than those reported from the tests in porous media. It is well-known that the foam generation and stabilization in bulk are different than that in porous media. Such understanding means the results obtained from these tests might not correlate with each other, and this is the case here. The bulk foam results pointed out that the aqueous solutions containing $\mathrm{CaCl}_{2}$ salt showed longer foam life with the anionic

\section{Surfactant 3}

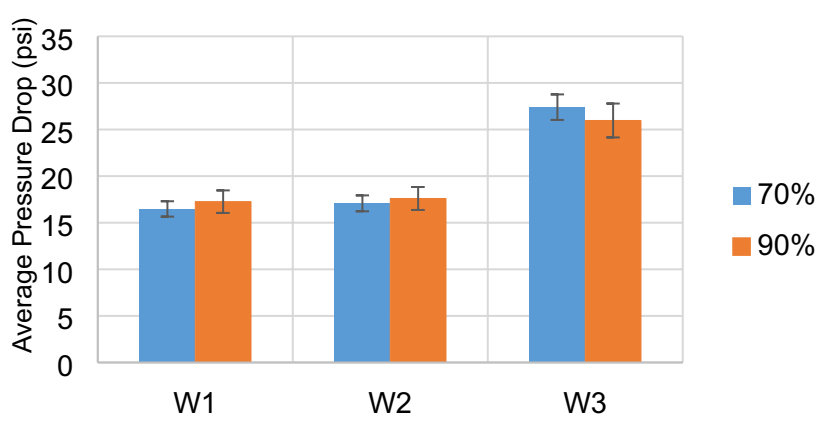

Fig. 13 Average pressure drop values recorded across microfluidic chip during flow of $\mathrm{CO}_{2}$ foam produced using surfactant 3 solution at $70 \%$ and $90 \%$ foam quality in different aqueous solutions 
surfactant and very weak foam with the nonionic surfactant. The solutions with $\mathrm{MgCl}_{2}$ and $\mathrm{CaCl}_{2}$ salts displayed higher impact on foam stability in comparison with $\mathrm{NaCl}$ with the amphoteric alkyl amine surfactant. Less stable foams were generated with aqueous solutions comprising of both magnesium and calcium ions. In the microfluidic model, the solutions containing $\mathrm{MgCl}_{2}$ salt produced more stable and viscous foams when compared to those produced using $\mathrm{NaCl}$ and $\mathrm{CaCl}_{2}$ salts.

The impact of electrolyte concentration as well as electrolyte nature on foam stability is ambiguous (Majeed et al. 2020). This is mainly due to the existence of so many parameters other than the electrolyte concentration and electrolyte type that can influence the foam generation and stabilization. Surfactant type, critical micelle concentration (CMC) of surfactants, and the used concentration of surfactants are some of these parameters that can affect foam stability in the presence of electrolytes. However, the important point to note here is that the present study clearly demonstrated the impact of different aqueous ions in the tailored water chemistry formulation on foam generation and stabilization. These new findings obtained with different aqueous ions in the injection water on foam stabilization with different type of surfactants could enable the selection and optimization of the right injection water chemistry and suitable chemicals for foam field applications.

\section{Conclusions}

In this study, three water recipes (W1, W2, and W3) and three surfactants (surfactant 1,2 and 3) were used to evaluate the effect of different aqueous ions in the selected tailored water chemistry formulations on foam stabilization and mobility control. Static (bulk foam test) and dynamic (mobility in porous media) foam tests were conducted to perform the comparative assessment among different water recipes. The results clearly demonstrated the effect of different aqueous ions on both foam stability and strength. Based on the analyses of experimental data, the major findings can be summarized as the following.

- Different foam behaviors were observed from the bulk foam tests and the foam in porous media.

- The bulk foam results revealed that the aqueous solutions containing calcium chloride salt $\left(\mathrm{CaCl}_{2}\right)$ showed better foam stability and longer foam life with the anionic surfactant and less stable foams with the nonionic surfactant solutions.

- Less stable foams were generated with aqueous solutions containing magnesium chloride $\left(\mathrm{MgCl}_{2}\right)$ and calcium chloride salts in comparison to sodium chloride $(\mathrm{NaCl})$ with the amphoteric surfactant.

- In the microfluidic model, the solutions containing $\mathrm{MgCl}_{2}$ produced more stable and viscous foams when compared to those produced using $\mathrm{NaCl}$ and $\mathrm{CaCl}_{2}$. The foam solutions obtained using $\mathrm{MgCl}_{2}$ showed higher resistance to gas flow and subsequently higher mobility reduction factor for the injection gas.

Acknowledgements The authors would like to acknowledge Amin Alabdulwahab, Othman Swaie, and Abdulkaream Algadrah for their help with the experimental works.

Funding The authors received no financial support for this research.

\section{Declaration}

Conflict of interest On behalf of all the co-authors, the corresponding author states that there is no conflict of interest.

Open Access This article is licensed under a Creative Commons Attribution 4.0 International License, which permits use, sharing, adaptation, distribution and reproduction in any medium or format, as long as you give appropriate credit to the original author(s) and the source, provide a link to the Creative Commons licence, and indicate if changes were made. The images or other third party material in this article are included in the article's Creative Commons licence, unless indicated otherwise in a credit line to the material. If material is not included in the article's Creative Commons licence and your intended use is not permitted by statutory regulation or exceeds the permitted use, you will need to obtain permission directly from the copyright holder. To view a copy of this licence, visit http://creativecommons.org/licenses/by/4.0/.

\section{References}

Al-Hashim HS, Celik MS, Oskay MM et al (1988) Adsorption and precipitation behaviour of petroleum sulfonates from Saudi Arabian limestone. J Petrol Sci Eng 1(4):335-344

Almajid M, Kovscek A (2016) Pore-level mechanics of foam generation and coalescence in the presence of oil. Adv Coll Interface Sci 233:65-82. https://doi.org/10.1016/j.cis.2015.10.008

Almajid M, Kovscek A (2020) Pore network investigation of trapped gas and foam generation mechanisms. Transp Porous Media 131(1):289-313. https://doi.org/10.1007/s11242-018-01224-4

AlMatouq H, Almubarak M, Algadrah A et al. (2020) A study on the adsorption behavior of different surfactants in carbonate using different techniques. Presented at the SPE Europec featured at 82nd EAGE conference and exhibition, Amsterdam, The Netherlands, 8-11 December. SPE-200566-MS. doi: https://doi.org/10.2118/ 200566-MS

Almobarky MA, AlYousif Z, Schechter D (2020) Gas/water foams stabilized with a newly developed anionic surfactant for gas mobility control applications. Pet Sci. https://doi.org/10.1007/ s12182-020-00437-x

Almubarak T, AlKhaldi M, Ng JH et al (2019) Design and application of high-temperature raw-seawater-based fracturing fluids. SPE J. 24(04):1929-1946. https://doi.org/10.2118/195597-PA 
Alotaibi MB, Nasr-El-Din HA, Fletcher JJ (2011) Electrokinetics of limestone and dolomite rock particles. SPE Res Eval Eng 14(05):594-603. https://doi.org/10.2118/148701-PA

AlSofi AM, Wang J, and Kaidar ZF (2018) Smartwater synergy with chemical EOR: effects on polymer injectivity, retention and acceleration. Presented at the SPE EOR conference at oil and gas West Asia, Muscat, Oman, 26-28 March. SPE-190394-MS. doi: https:// doi.org/10.2118/190394-MS

AlYousef Z, and Schechter D (2019) The synergy of surfactant and nanoparticles: towards enhancing foam stability. In: Paper presented at the SPE Kuwait oil \& gas show and conference, Mishref, Kuwait. https://doi.org/10.2118/198190-MS

AlYousef ZA, Almobarky MA, Schechter DS (2020a) Surfactant and a mixture of surfactant and nanoparticles to stabilize $\mathrm{CO} 2 /$ brine foam, control gas mobility, and enhance oil recovery. J Petrol Explor Prod Technol 10:439-445. https://doi.org/10.1007/ s13202-019-0695-9

AlYousef Z, Ayirala S, Gizzatov A et al (2020b) Evaluating foam stability using tailored water chemistry for gas mobility control applications. J Petrol Sci Eng 195:107532. https://doi.org/10. 1016/j.petrol.2020.107532

Ayirala S, Yousef A (2015) A state-of-the-art review to develop injection-water-chemistry requirement guidelines for IOR/EOR projects. Soc Petrol Eng. https://doi.org/10.2118/169048-PA

Babadagli T (2020) Philosophy of EOR. J Petrol Sci Eng 188:106930. https://doi.org/10.1016/j.petrol.2020.106930

Bera A, Belhaj H (2016) Application of nanotechnology by means of nanoparticles and nanodispersions in oil recovery-a comprehensive review. J Nat Gas Sci Eng 34:1284-1309. https://doi. org/10.1016/j.jngse.2016.08.023

Campbell BT, Orr FM (1985) Flow visualization for CO2/crude-oil displacements. Soc Petrol Eng J 25(05):665-678. https://doi. org/10.2118/11958-PA

Chiang JC, Sawyal SK, Castanier LM, Brigham WE, and Arshad Sufi (1980) "Foam as a mobility control agent in steam injection processes." Paper presented at the SPE California regional meeting, Los Angeles, California. doi: https://doi.org/10.2118/8912-MS

Eide $\varnothing$, Føyen T, Skjelsvik E, Rognmo A, Fern $\varnothing$ M (2018) Nanoparticle stabilized foam in harsh conditions for CO2 EOR. Soc Petrol Eng. https://doi.org/10.2118/193212-MS

Enick RM, Olsen DK, Ammer JR et al (2012) Mobility and conformance control for $\mathrm{CO} 2 \mathrm{EOR}$ via thickeners, foams, and gels-a literature review of 40 years of research and pilot tests. Presented at the SPE improved oil recovery symposium, Tulsa, Oklahoma, USA, 14-18 April. SPE-154122-MS. doi: https:// doi.org/10.2118/154122-MS

Falls A, Hirasaki G, Patzek T et al (1988) Development of a mechanistic foam simulator: the population balance and generation by snap-off. SPE Res Eng 3(03):884-892. https://doi.org/10. 2118/14961-PA

Farajzadeh R, Muruganathan R, Krastev R, Rossen WR (2010) Effect of gas type on foam film permeability and its implications for foam flow in porous media. Soc Petrol Eng. https://doi.org/10. 2118/131297-MS

Farajzadeh R, Andrianov A, Krastev R, Hirasaki G, Rossen WR (2012) Foam-oil interaction in porous media: implications for foam assisted enhanced oil recovery. Soc Petrol Eng. https://doi. org/10.2118/154197-MS

Figdore PE (1982) Adsorption of surfactants on kaolinite: $\mathrm{NaCl}$ versus $\mathrm{CaCl} 2$ salt effects. J Colloid Interface Sci 87(2):500-517

Fuseni AB, AlSofi AM, AlJulaih AH et al (2018) Development and evaluation of foam-based conformance control for a high-salinity and high-temperature carbonate. J Petrol Explor Prod Technol 8:1341-1348. https://doi.org/10.1007/s13202-018-0431-x

Grigg RB, Baojun B, and Yi L (2004) Competitive adsorption of a hybrid surfactant system onto five minerals, berea sandstone, and limestone. Presented at the SPE annual technical conference and exhibition, Houston, Texas, 26-29 September. SPE90612-MS. doi: https://doi.org/10.2118/90612-MS

Holbrook, OC (1958) Gas drive oil recovery process. U.S. Patent no. 2,866,507. U.S. patent and trademark office, Washington, DC

Kapetas L, Vincent Bonnieu S, Danelis S, Rossen WR, Farajzadeh R, Eftekhari AA, Kamarul Bahrim RZ (2015) Effect of temperature on foam flow in porous media. Soc Petrol Eng. https://doi. org/10.2118/172781-MS

Kovscek AR, Radke CJ (1994) Fundamentals of foam transport in porous media. Foams fundamentals and applications in the petroleum industry. Advances in chemistry. American Chemical Society, pp 115-163

Lee SY, Webb KJ, Collins I, et al. (2010) Low salinity oil recovery: increasing understanding of the underlying mechanisms. Presented at the SPE improved oil recovery symposium, Tulsa, Oklahoma, USA, 24-28 April. SPE-129722-MS. doi: https:// doi.org/10.2118/129722-MS

Liu M, Andrianov A, and Rossen WR (2011) Sweep efficiency in $\mathrm{CO} 2$ foam simulations with oil. Presented at the SPE EUROPEC/EAGE annual conference and exhibition, Vienna, Austria, 23-26 May. SPE-142999-MS. doi: https://doi.org/10.2118/ 142999-MS

Malysa K, Lunkenheimer K (2008) Foams under dynamic conditions. Curr Opin Colloid Interface Sci 13:150-162

Mannhardt K, Schramm LL, Novosad JJ (1993) Effect of rock type and brine composition on adsorption of two foam-forming surfactants. SPE Adv Technol Ser 1(1):212-218

Manrique EJ, Thomas CP, Ravikiran R et al. (2010) EOR: current status and opportunities. Presented at the SPE improved oil recovery symposium, Tulsa, Oklahoma, USA, 24-28 April. SPE-130113-MS. doi: https://doi.org/10.2118/130113-MS

Masalmeh SK, Hillgartner H, Al-Mjeni RA et al. (2010) Simultaneous injection of miscible gas and polymer (SIMGAP) to improve oil recovery and sweep efficiency from layered carbonate reservoirs. Presented at the SPE EOR conference at oil \& gas West Asia, Muscat, Oman, 11-13 April. SPE-129645-MS. doi: https://doi.org/10.2118/129645-MS

Nasralla RA, Alotaibi MB, and Nasr-El-Din HA (2011) Efficiency of oil recovery by low salinity water flooding in sandstone reservoirs. Presented at the SPE Western North American region meeting, Anchorage, Alaska, USA, 7-11 May. SPE-144602-MS. doi: https://doi.org/10.2118/144602-MS

Osode PI, Almubarak TA, Bataweel MA et al. (2015) Assessment of water injection-related scale risks for an onshore carbonate oilfield incremental development project in central Arabia. Presented at the SPE Saudi Arabia section annual technical symposium and exhibition, Al-Khobar, Saudi Arabia, 21-23 April. SPE-178000-MS. doi: https://doi.org/10.2118/178000-MS

Phukan R, Gogoi SB, Tiwari P (2020) Effects of CO2-foam stability, interfacial tension and surfactant adsorption on oil recovery by alkaline-surfactant-alternated-gas, $\mathrm{CO} 2$ flooding. Coll Surf A 597:124799. https://doi.org/10.1016/j.colsurfa.2020.124799 (ISSN 0927-7757)

Scheamm LL, Wassmuth F (1994) Foams: basic principles. In: Schramm LL (ed) Foams: fundamentals and applications in the petroleum industry. American Chemical Society, Washington, DC, USA

Shabib-AsL A, Abdalla Ayoub M, Abdalla Elraies K (2019) Combined low salinity water injection and foam flooding in sandstone reservoir rock: a new hybrid EOR. Soc Petrol Eng. https:// doi.org/10.2118/194975-MS

Singh R, Mohanty KK (2016) Foams with wettability-altering capabilities for oil-wet carbonates: a synergistic approach. Soc Petrol Eng. https://doi.org/10.2118/175027-PA 
Talha M, Sølling TI, Kamal MS (2020) Foam stability: the interplay between salt-, surfactant- and critical micelle concentration. J Petrol Sci Eng 187:106871. https://doi.org/10.1016/j.petrol. 2019.106871 (ISSN 0920-4105)

Teklu T, Alameri W, Graves R et al (2016) Low-salinity water-alternating-CO2 EOR. J Petrol Sci Eng 142:101-118. https://doi.org/ 10.1016/j.petrol.2016.01.031

Wang B, Sun L, Shi M et al (2018) Mobility control ability and stability investigation of nitrogen foam under high temperature and high salinity condition. J Petrol Explor Prod Technol 8:547552. https://doi.org/10.1007/s13202-017-0365-8

Webb K, Black C, and Al-Ajeel H (2004) Low salinity oil recovery-log-inject-log. Presented at the SPE/DOE symposium on improved oil recovery, Tulsa, Oklahoma, 17-21 April. SPE89379-MS. doi: https://doi.org/10.2118/89379-MS

Whorton LP, Brownscombe ER, and Dyes AB (1952) "Method for producing oil by means of carbon dioxide," U.S. patent $2,623,596$
Whorton LP, Kieschnick WF (1950) A preliminary report on oil recovery by high-pressure gas injection. Drilling and production practice, American Petroleum Institute, NewYork, USA

Yousef A, and Ayirala S (2014) A novel water ionic composition optimization technology for smartwater flooding application in carbonate reservoirs. Presented at the SPE improved oil recovery symposium, Tulsa, Oklahoma, USA, 12-16 April. SPE169052-MS. doi: https://doi.org/10.2118/169052-MS

Yousef AA, Liu JS, Blanchard GW et al. (2012) Smart waterflooding: industry. Presented at the SPE annual technical conference and exhibition, San Antonio, Texas, USA, 8-10 October. SPE159526-MS. doi: https://doi.org/10.2118/159526-MS

Publisher's Note Springer Nature remains neutral with regard to jurisdictional claims in published maps and institutional affiliations. 